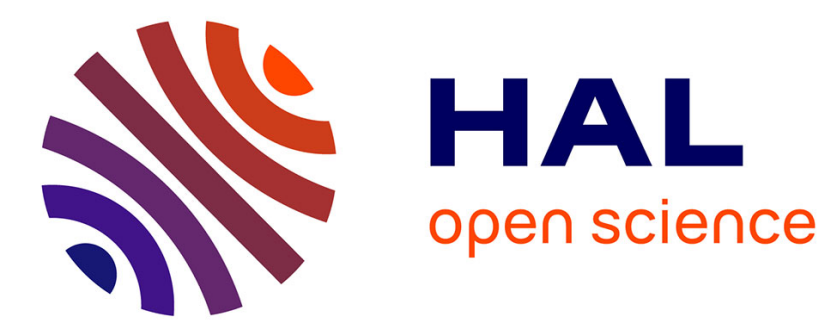

\title{
Power-Aware Regeneration Algorithm in Flex-grid Networks
}

Matthieu Kanj, Esther Le Rouzic, Bernard Cousin

\section{To cite this version:}

Matthieu Kanj, Esther Le Rouzic, Bernard Cousin. Power-Aware Regeneration Algorithm in Flex-grid Networks. 43rd European Conference on Optical Communication (ECOC 2017), Sep 2017, Gothenburg, Sweden. hal-01543930

\section{HAL Id: hal-01543930 https://hal.science/hal-01543930}

Submitted on 21 Jun 2017

HAL is a multi-disciplinary open access archive for the deposit and dissemination of scientific research documents, whether they are published or not. The documents may come from teaching and research institutions in France or abroad, or from public or private research centers.
L'archive ouverte pluridisciplinaire HAL, est destinée au dépôt et à la diffusion de documents scientifiques de niveau recherche, publiés ou non, émanant des établissements d'enseignement et de recherche français ou étrangers, des laboratoires publics ou privés. 


\title{
Power-Aware Regeneration Algorithm in Flex-grid Networks
}

\author{
Matthieu Kanj(1), Esther Le Rouzic ${ }^{(2)}$, Bernard Cousin ${ }^{(1)(3)}$, \\ (1) bcom, Network Interfaces Lab, Cesson-Sevigne, France. matthieu.kanj@b-com.com \\ (2) Orange Labs Lannion, Lannion, France. esther.lerouzic@orange.com \\ (3) IRISA Labs, University of Rennes 1, Rennes, France. bernard.cousin@irisa.fr
}

\begin{abstract}
Flex-grid technology increases network links capacity and optical power levels, creating power saturation problem in legacy amplifiers. We demonstrate that optimizing regeneration sites allows reducing the optical power of highly loaded links, avoiding amplifiers saturation over the existing fixedgrid networks.
\end{abstract}

\section{Introduction}

Flex-Grid is a promising technology that allows better spectral efficiency and spectrum usage in optical networks. It offers the possibility to create additional channels in the same available bandwidth ( $\mathrm{C}$ band) and thus improving network capacity. However, this capacity increase may not be sustainable, because of the associated increase in optical amplification power ${ }^{1}$. In fact, the increasing number of optical channels gives rise to a power saturation problem in legacy amplifiers when migrating from fixed-grid to flex-grid networks ${ }^{2,3}$.

We demonstrated in ${ }^{2,3}$ that avoiding saturation problem is possible through adapting channels optical power. This adaptation is possible by converting the OSNR margins $\left(O S N R_{\text {margin }}\right)$ into optical power attenuation over optical links ${ }^{1,4}$. However, this power saturation can always arise over highly loaded links as demonstrated in ${ }^{5}$, especially when there is no sufficient exploitable OSNR margins.

In fact, the $O S N R_{\text {margin }}$ is an important parameter to optimize network performance and to increase its capacity as demonstrated in many works in the literature ${ }^{6,7}$. It gives the possibility to optimize different transmission parameters, such as modulation format, optical power, baud/bit rates and coding scheme. In this work, we consider only the channel power adaptation, in order to reduce the power level over highly loaded links and avoid power saturation. The higher is the $O S N R_{\text {margin }}$, the higher is the power attenuation that can be applied to an optical channel ${ }^{5}$.

In this paper, we will show how regeneration sites impact the OSNR margins of established channels. Then, we present through an example the execution result of the developed poweraware regeneration algorithm (PAR). Finally, the performance of the algorithm is evaluated.

\section{Power-aware regeneration algorithm}

Let's assume that an optical channel must be established between a node $\mathrm{A}$ and a node $\mathrm{F}$ as shown in Figure 1. Moreover, we assume that signal regeneration is required in intermediate nodes. Therefore, depending on the goal of the applied regeneration algorithm, several regeneration sites can be designated accordingly.

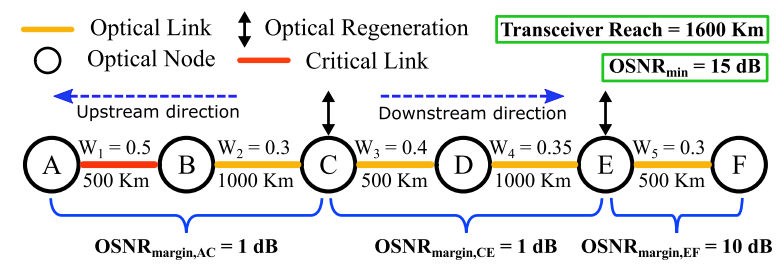

Fig. 1: Selected regeneration sites with traditional algorithm

The goal of the PAR algorithm is to reduce the blocking due to power saturation while guaranteeing the minimum number of regeneration sites. In fact, this goal can be achieved through maximizing the $O S N R_{\text {margin }}$ of the candidate lightpath over the segment containing the optical link having the highest power level. This link is identified through its power ratio $\left(W_{l}=P_{\text {real }, l} / P_{\max , l}\right)$, which is equal to the current aggregated link power $\left(P_{\text {real }, l}\right)$ divided by the maximum power level $\left(P_{\max , l}\right)$ allowed over the link $l$ (as defined by the link design $\left.{ }^{5}\right)$.

Figure 1 shows the execution result of the traditional regeneration placement algorithm ${ }^{8}(\mathrm{TR})$ for a candidate optical channel between node $A$ and $F$. In this case, the regeneration sites (i.e., $\mathrm{C}$ and E) are computed by exploiting the maximum reach of the optical transceiver, guaranteeing minimum number of regeneration sites (i.e., minimum cost). In this example, the highest power attenuation is performed over the segment EF, since it have the highest $O S N R_{\text {margin }}$ $\left(O S N R_{\text {margin }, E F}=10 \mathrm{~dB}\right)$.

The PAR algorithm solution will place a regenerator in node $B$ and $D$ as shown in Figure 2. 
This regeneration combination allows having minimum number of regeneration sites, and a maximum $O S N R_{\text {margin }}$ over the transparent segment including the critical link $\mathrm{AB}(W=0.5)$.

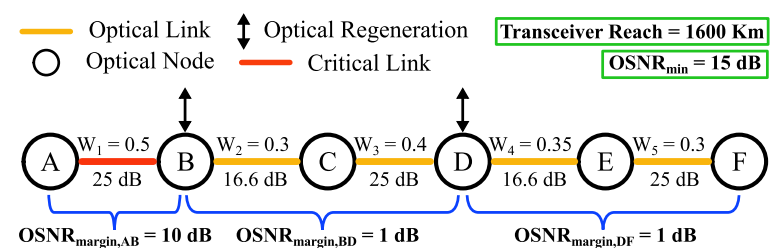

Fig. 2: Selected regeneration sites with PAR algorithm

Therefore, if we consider the selected regeneration sites of the Figure 2, the power attenuation that can be applied over the link $A B$ is higher than the one that can be applied with the regeneration sites of Figure $1\left(O S N R_{\text {margin }, A C}=1 \mathrm{~dB}\right.$ $<O S N R_{\text {margin, } A B}=10 \mathrm{~dB}$ ). Thus, the added optical power over the link $A B$ is minimized after the establishment of the optical channel, which was not the case with the TR algorithm.

Functional description of PAR algorithm

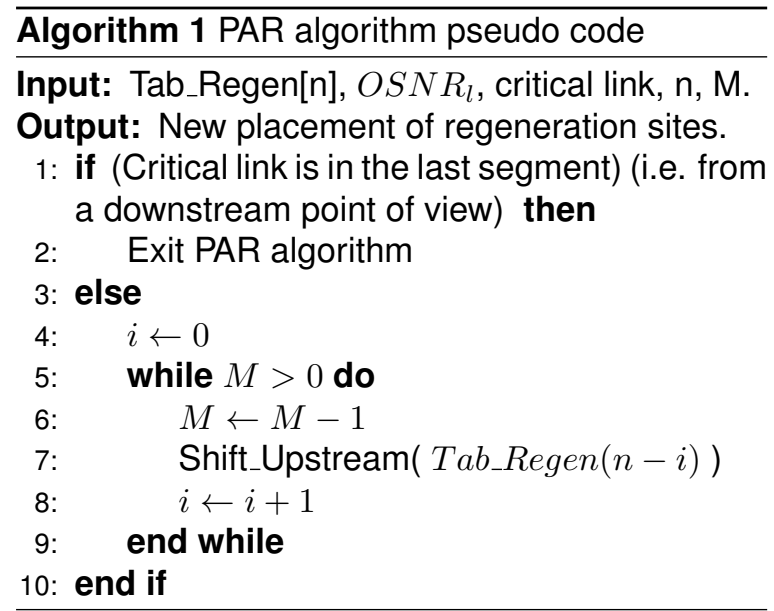

The PAR algorithm takes as an input the regeneration sites computed by the TR algorithm (Tab_Regen[n]), the OSNR of every link constituting the optical path $\left(O S N R_{l}\right)$, the critical link, the number of regeneration sites $n$ and a variable $M$. The critical link is identified through its power ratio calculated at the time of reception of channel connection request, and $M$ is the number of transparent segments in the downstream direction relative to the critical link ( $M=2$ in Figure 1). The algorithm tests first if the critical link is in the last segment. If yes, there is nothing to do, since TR algorithm guarantees maximum $O S N R_{\text {margin }}$ for the last segment. If the critical link is in other segment, the algorithm will shift as much as possible the regeneration sites $n-i$ in the upstream direction (e.g., Tab_Regen(2-0) = E in Figure 1).

\section{Simulation setup and scenarios}

In order to evaluate the PAR algorithm, we improved our distributed GMPLS-based network simulator ${ }^{5}$ to take into account of optical regeneration. Simulations are performed over the European backbone network of Figure 3, considering the same link design ( 80 channels of $50 \mathrm{GHz}$ per link over a fixed-grid network infrastructure), filtering penalties, channels types and minimum acceptable OSNR ( $15 \mathrm{~dB}$ ) as in ${ }^{5}$. In order to simplify the analysis of results, only $100 \mathrm{Gbit} / \mathrm{s}$ optical channels (occupying $37.5 \mathrm{GHz}$ each) are established in simulated scenarios. Three scenarios are considered:

- Flex-grid with power adaptation with TR algorithm (FX3S_TR).

- Flex-grid with power adaptation with PAR algorithm (FX3S_PAR).

- Flex-grid with TR algorithm and unlimited link power resources (FX3S_TR_Full): This is a bench mark scenario. It is considered to evaluate the power saturation problem. In this scenario, no optical power limitation is considered over network links (i.e., no blocking will occur due to power saturation).

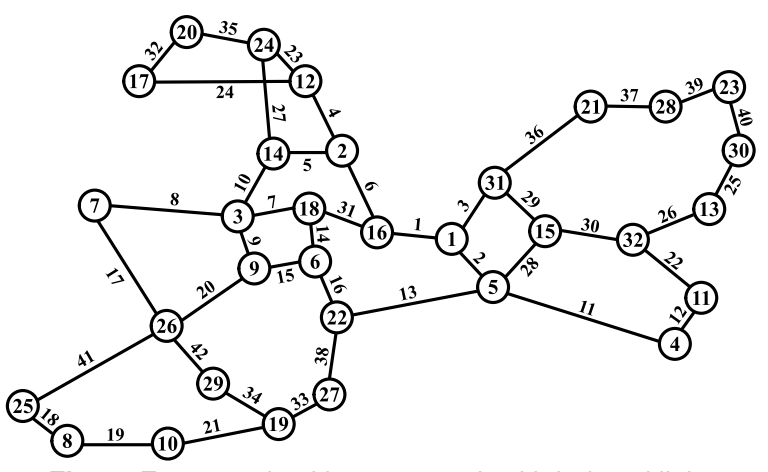

Fig. 3: European backbone network with indexed links

Scenarios were simulated considering a dynamic connection establishment, where optical connections are established and released automatically. Connection requests are dynamically generated following a Poisson process, where every sourcedestination pair of each request is randomly chosen among all network nodes according to a uniform distribution. The inter-arrival and holding times for every request follow an exponential distribution with averages of $1 / \lambda$, and $1 / \mu$, respectively. The connection holding time $1 / \mu$ is fixed to $100 \mathrm{~s}$. The offered network load is obtained by varying $1 / \lambda$.

\section{Simulation results and discussions}

We consider the blocking probability as an evaluation criterion. It is expressed as the ratio between the number of blocked lightpaths and the number of requested lightpaths. Simulation result for blocking probability is plotted as a function of the total network load defined as $N \times \lambda / \mu$, where 


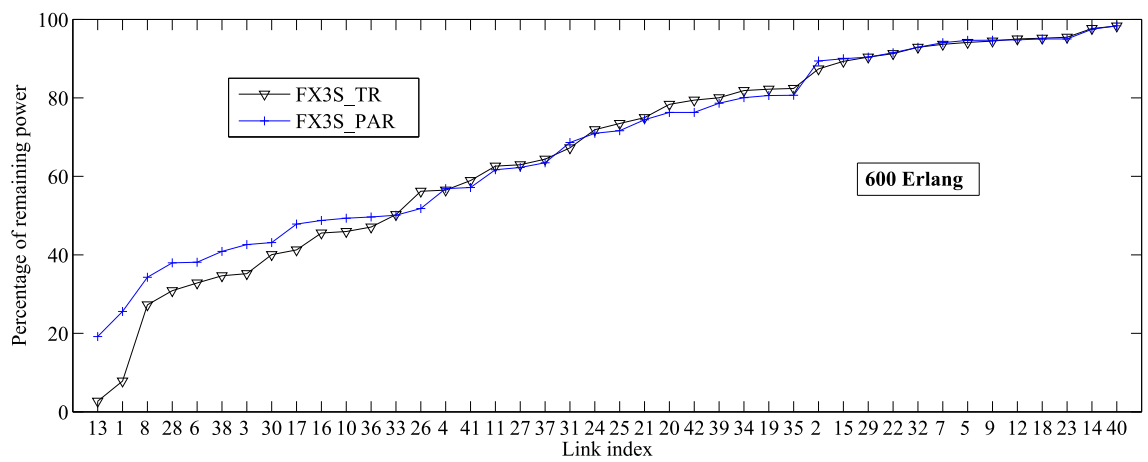

Fig. 5: Percentage of the remaining optical power per link

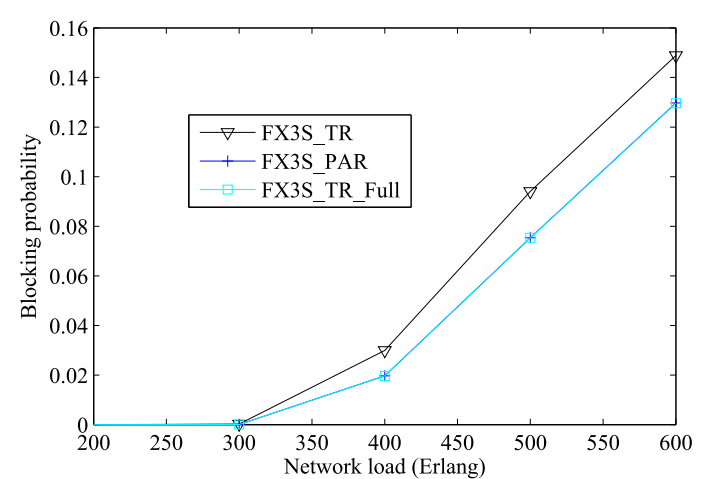

Fig. 4: Blocking probability versus Network load

$N=32$ is the number of network nodes, and the load is expressed in Erlang. We can notice from Figure 4, that the scenario FX3S_PAR using the PAR algorithm have less blocking in comparison with FX3S_TR scenario. This indicates first that the PAR algorithm succeeded to reduce the aggregated optical power level over the highly powered links that were causing the power saturation problem. Moreover, it can be seen that FX3S_PAR performs the same blocking probability as FX3S_TR_Full scenario. This means that the power saturation problem is no longer occurring and thus the spectral limitation is the only reason of blocking.

This analysis is confirmed in Figure 5, where we plotted the remaining optical power level of network links. Figure 5 shows the percentage of the remaining optical power over each link of the network before and after the use of the PAR algorithm. We have in black the percentage of the remaining optical power (sorted in ascending order) for FX3S_TR scenario, and in blue the percentage of the remaining optical power for the same links for FX3S_PAR scenario. It can be noticed that the PAR algorithm succeeded in reducing the optical power level of the highly loaded links (i.e. the links having the lowest remaining optical power), consequently increasing their remaining power level (e.g., link 13 and 1). In fact, the PAR algorithm balances the power level distribution over network links: the power level of the highly used links is reduced while the power level of lightly-used link is increased. This result demonstrates the advantage of exchanging $O S N R_{\text {margin }}$ between the transparent segments constituting an optical path allowing OSNR margins to be transferred to the links that need it most.

\section{Conclusions}

In this paper, we have addressed the power saturation problem when migrating to flexible networks. We have proposed a power-aware regeneration algorithm that allows reducing the power level over highly loaded links and thus avoiding amplifiers saturation. Simulations revealed that adding power information in the regeneration algorithm of the control plane allows optimizing the power level of network links and thus exploiting more efficiently their power resources. More interestingly, we have shown that optimizing regeneration sites can be an effective way to exploit more efficiently the OSNR margins of optical links in order to increase network capacity.

\section{References}

[1] J. L. Augé., "Can we use flexible transponders to reduce margins?," Proc. OFC, pp. 1-3, 2013.

[2] D. Amar et al., "On the legacy amplifier limitation in flexgrid optical networks," Proc. PS, pp. 172-174 (2015).

[3] M. Kanj et al., "Optical power control to efficiently handle flex-grid spectrum gain over existing fixed-grid network infrastructures," Proc. ICNC, pp. 1-7, Kauai(USA), 2016.

[4] Y. Pointurier., "Design of low-margin optical networks," IEEE/OSA JOCN., Vol. 9, no. 1, pp. 9-17 (2017).

[5] M. Kanj et al., "Optical power control in GMPLS control plane," IEEE/OSA JOCN., Vol. 8, no. 8, pp. 553-568 (2016).

[6] D. J. Ives et al., "Assessment of options for utilizing SNR margin to increase network data throughput," Proc. OFC, M2I.3, pp. 1-3, Los Angeles (2015).

[7] D. J. Ives et al., "Adaptive Transceivers in Nonlinear Flexible Networks," Photon. Netw. Commun., Vol. 29, no. 3, pp. 244-256 (2015).

[8] N. Sambo et al., "Accounting for Shared Regenerators in GMPLS-Controlled Translucent Optical Networks," J. Lightwave Technol., Vol. 27, no. 19, pp. 4338-4347 (2009). 